\title{
3-DIMENSIONS OF INTERACTIVE MULTIMEDIA VALIDITY TO INCREASE VISUAL-SPATIAL INTELLIGENCE IN MOLECULAR GEOMETRY
}

\author{
Abdul Aziz Tamami dan Kusumawati Dwiningsih \\ Program Studi Pendidikan Kimia Universitas Negeri Surabaya \\ email: kusumawatidwiningsih@unesa.ac.id
}

\begin{abstract}
The research aimed to find out the properness of the 3-dimensions (3D) interactive multimedia as the learning media to increase student's visuospatial intelligence in molecular geometry. This research and development used design of 4D by Thiagarajan that was modified by Ibrahim. Modified design implemented until third step (development phase). The research subject was $10^{\text {th }}$-grade students that were getting molecule shapes geometry sub-matter. The 3D interactive multimedia was declared as valid based on the expert judgement through validation process by three validators consisting of 2 lecturers and 1 chemistry teacher. The content and construct validity sheet are used as an instrument on the validation process. Multimedia validity can be avowed from content validity and construct validity. The content validity was determined by the content standard and content systematic criteria including usefulness in promoting students' visuospatial intelligence. The construct validity was determined by software techniques and visual communication. Validation result data was used quantitative descriptive analysis. According to the validation result, the content and construct validity percentage results as $81 \%$ and $84 \%$ at the more valid category, so that $3 \mathrm{D}$ interactive multimedia can be declared valid as a learning media. The media will be useful to improve the learning quality.
\end{abstract}

Keyword: 3D interactive media, visual-spatial intelligence. molecular geometry

\section{NTRODUCTION}

Chemistry is the natural science that explains the matter and its changes in nature. Chemistry is commonly known as central natural science because the role is closed to our daily life (Manahan, 2017, p. 56). It also can connect between one study to other natural sciences through it. This role makes this subject has three representation levels of skill that consist of macroscopic, sub-microscopic, and symbolic levels (Becker, Stanford, Towns, \& Cole, 2015). The macroscopic level is representation level form as fact phenomenon and can be observed, such as chemistry changes phenomenon in daily life. The sub- microscopic level is a representation level based on the real observation but still needs some theories to explain what occurred in the molecular part using theoretic representation, such as microscopic particles that cannot be seen directly. The symbolic level is a representation based on the fact and converted into some simple mark, such as symbol representation from the atom, molecule, and compounds in figure, algorithm, and computer processing forms. It makes this study is also classified as a difficult subject by the students. It causes various skills that are needed by students to understand it. Furthermore, the subject matter that has different levels 
makes the students mostly not interesting in the chemistry learning process. This study is composed of fundamental matters such as the atomic structure, periodic table system, chemical bonding, stoichiometry, and others that have abstract concepts.

The main chemistry studies mastery especially chemistry bonding studies properly needed to understand the whole chemistry studies. Chemistry bonding is one of the main chemistry studies that have a role in the chemistry changes process (Ghibaudi, Cerruti, \& Villani, 2019). This matter can be understanding if the students have a good representational skill. Chemical bonding characteristics are tendency onto sub-microscopic and symbolic levels. The skill at this level can represent the factual phenomenon that cannot be observed by human sense. As an alternative, the symbols, signs, and marks are used to represent the molecule and the compound in the real condition. The molecular geometry is the sub-matter in the chemical bonding matter. This submatter explains the variety of molecular shapes can affect their characteristics such as their interactions and properties. It makes the representational skills also needed by students to be mastery of this sub-matter. Visualization of molecular shapes in the learning process is properly needed to understand the kind of shapes and angles to make students' comprehension.

Representational skills and visualization process are the two main parts that can be connected by visuospatial intelligence. This visuospatial intelligence refers to a person's capacity to identify visual and spatial relationships among objects. Visuospatial ability is measured in terms of the ability to imagine objects, to make global shapes by locating small components or to understand the differences and similarities between objects (Trés \&
Brucki, 2014). Visuospatial intelligence is also one of intelligence that enables one to visualize information and synthesize data and concepts into visual metrics or images (Suprapto, bin Ahmad, Chaidir, Ardiansyah, \& Diella, 2018). The urgencies of visuospatial intelligence in the chemistry learning process related to the student's representational skills development. It confirmed by (Sunyono \& Sudjarwo, 2018) that says the chemistry learning that combines the transforming process of the sub-microscopic representation (visual) into verbal and symbolic or vice versa can help the student better to gain the concept quickly. Also, the students can represent the molecular shapes definitely if they have high visuospatial intelligence (Wu $\&$ Shah, 2014). There is various method to increase visuospatial intelligence in chemistry learning. The major method is showing chemical dynamics and properties interactively and visualization chemical properties between 2 dimensions and 3 dimensions. It also is supported by Carlisle, Tyson, and Nieswandt (2015) that state three method that increase visuospatial intelligence consist of showing symmetrical planes, visualizing the transformation between 2 and 3 dimension, and translating molecular shapes from formula into symbolic shapes.

Visuospatial intelligence is including into the students' difficulties when learning chemistry. It proved by the national examination on senior high school 2018 at chemistry subject outcomes, the result percentage of completeness as $50.56 \%$ under minimal categorized as 55\%. In case, the result percentage of chemical bond in national examination 2018 as $51.50 \%$ that means low completeness in the chemical bond concept. It indicates that the students still have difficulties caused by the stagnant development of visuospatial intelligence. It 
confirmed by Sunyono and Sujarwo (2018) that says the majority of high school students still have an understanding of chemistry at the macro level, the ability of reasoning is only able to produce a very simple mental model that is still in the low category. It also corresponds with the findings of the students' questionnaire that shows $66 \%$ of the students are uninteresting with chemistry learning and $44 \%$ completeness of pretest results. It related with (McCollum, Regier, Leong, Simpson, \& Sterner, 2014) findings that states cannot reason, represent and interpret the phenomenon of sub-microscopic concepts of atomic structure can blunt the power of students' mental models in understanding chemical phenomena become less well established. In teacher perspective, based on the result of the chemistry teacher interviewing process, it found that classroom learning has been limited to lecture methods, the use of physically learning media such as molecular shapes models (molymod) is limited, and digitally also limited with the use of a PowerPoint slides that contain a description of the material. It indicates less representation in sub-microscopic and symbolic with a less appealing look for students. Furthermore, based on Merchant et al. (2013) findings that show the imagination of the students has not focused properly, the ability to draw and describe the phenomena of atomic structure deviates from the supposed image.

These outcomes are not corresponding with the rules of Indonesia Education and Culture Minister on number 68 in 2014 that states to create a learning atmosphere and process actively, the teachers are expected to use various learning resources to maximize the student's potential development. Learning resources need to be supported by the use of information and communication technology that can explore effective and efficient learning resources.

The teacher and the student in this era should adapt and explore various learning resources. The creativity of the teachers when choosing and using learning resources learning has important rules in molecular geometry learning. Learning resources can be applied to visuospatial intelligence development. Representational learning could stimulate the students to be actively engaged to solve chemical problems especially to interpret and to transform macro, sub-micro, and symbolic phenomena. Moreover, based on Sunyono and Meristin (2018) findings, the students were allowed to observe a demonstration of animation activities, analyzing submicro visual images, and building concepts through reasoning to improve mastery of their concepts. These activities can occur when using suitable learning media.

Based on the explanation before, it required a learning media that can increase visuospatial intelligence through showing and visualizing the transformation of molecular geometry, so that this learning media can help the students to get a better understanding.

Based on the reason that explained, it needed the development of interactive multimedia based on 3-dimensional visualization to increase students' visuospatial intelligence, and their interest in molecule shapes geometry learning. A 3D interactive multimedia is software with format $h \mathrm{html}$ that can be played in all kinds of computer browsers. It is portable to use in any computer device and shows molecule shapes geometry concept with the interactive feature, such as 3-dimensional molecule shapes that can take $360^{\circ}$ rotation, molecule shapes in 2 dimensions, and the exercise that can increase students' visuospatial intelligence. According to the background problem, it makes the research 
of interactive 3D multimedia validity to increase students' visuospatial intelligence in molecule shapes geometry properly needed to take it.

\section{METHOD}

This study used R\&D design development that refers to the development design of 4D Thiagarajan, which modified by Ibrahim (2001) in the development phase. The phase of this method consisted of 3 phases from define, design, and development.

The first phase was "define" that has the function to consider and determine the requirement of learning needs. To know it, the analysis process was needed to explain the need and requirements. In this phase, the analysis process is divided into 5 kinds of analysis that consist of curriculum analysis, student analysis, task analysis, concept analysis, and learning objectives. In curriculum analysis, curriculum 2013 that revised in 2016 is used as the learning base in the majority school in Indonesia. Cognitive core competence 3 and 4 in curriculum 2013 was focused on chemistry learning. It had the main scope to prepare the student to be creative and innovative on the industrial revolution 4.0 competition. In student analysis, the senior high school students have average age at 17 years old, based on Piaget's theory in the cognitive learning theory, the students at this age are categorized on the formal operation phase that can think abstract and dynamics. In this age, the students can control the navigation of multimedia that similar to using their gadget app. In concept analysis, molecular shape geometry sub-matter can be breakdown into two concepts the first is molecular shapes based on valence shell electron pair repulsion (VSEPR) theory and Hybridization theory. The two concepts have characteristics like representation and visualization molecular shape, it makes the visuospatial intelligence needed to make good representation. The good students' representation can be increased in chemistry learning with several methods like increase ability to understand molecular symmetry, visualize molecular shape from chemical formula to 3 dimensions, and translation molecular shape from 2 dimensions to 3 dimensions (Carlisle et al., 2015). Task analysis and objective learning is taking based on the curriculum analysis. Basic competence 3.6 is used as the foundation of learning objectives in this research.

The second phases was "design" that has the function to plan the media and the format used in this research. There were 4 steps to make a good plan format and media. There are criteria test creation, media selection, format selection, and first design media creation. The criteria test creation was the composition process to make learning media based on the learning objectives in the phase before. The media selection was the process to select a kind of media that suitable for the characteristic of sub-matter. Multimedia can combine text, graphics, audio, visual, and audio-visual. It made the students could easily represent molecular shapes. The format selection was used to know the best storyboard of multimedia that already chosen. The format multimedia can be divided into 5 formats such as a tutorial, drill and practice, simulation, experiment, and gamification (Daryanto, 2013, p. 166). The format that choosing is the tutorial, it suitable for the sub-matter characteristic that predicts molecular geometry. The first design media was created with many steps and tools, Inkscape 0.92.4 is the free graphic tools that use to create illustration and some assets in this multimedia, PowerPoint is used to create the simple 2-dimensional animation, Blender 3D is used to create the 
molecular shape model in 3-dimensional form, and Articulate Storyline 3 is used as the display engine that combines all assets like graphics, text, audio, video, and 3-dimensional molecular shape into one package software with the extension format.html. This format can be opened in all kinds of computer browsers that support html5 and java.

The last phase was "develop" that has the function to ensure the criteria of multimedia that suitablematter characteristics and can be implemented. Develop phase was consist of two steps, the first was the expert appraisal and development testing. The expert appraisal was the step that measures multimedia validity. In this step, the expert assessed the interactive multimedia through the study and validation process. The study process was the process of the expert provided suggestions about the first interactive multimedia design. After revision refers to expert suggestion, the validation process can behold. In this step, the validation sheet was used as the assessment instrument. The validity of multimedia can be proven by two criteria, content validity and construct validity. Content validity wass a validity criterion based on the matter of relevance with learning objectives and the curriculum. There were two aspects of this criterion, based on content states and its systematics (Baloyi, Ojo, \& Van Wyk, 2017, p. 67). The construct validity is the validity criterion based on the matter consistency that can be referred from software techniques and visual communication.

The validation process was carried out by 3 validators that consist of two chemistry lecturers and one chemistry teacher. The validation assessment used quantitative descriptive analysis. The criteria in the validation sheet used the Likert scale that was presented in Table 1.
Table 1

\begin{tabular}{lc}
\begin{tabular}{l} 
Likert Scale \\
\multicolumn{1}{c}{ Criteria }
\end{tabular} & Score \\
\hline Very Unsatisfied & 1 \\
Unsatisfied & 2 \\
Neutral & 3 \\
Satisfied & 4 \\
Very Satisfied & 5 \\
\hline
\end{tabular}

The validation result was converted from 3 validators to obtain the validation categories. The formula can be written like:

$$
P(\%)=\frac{\sum \text { score that obtained }}{\text { Maximum Score }} \times 100 \%
$$

Attachment:

$$
\begin{gathered}
\text { Score }=(\text { high score each item) } x \text { (the } \\
\text { amount of items) } x(3 \text { validators })
\end{gathered}
$$

The percentage result will be interpreted based on Table 2 that shown.

Table 2

Score Interpretation table (Arikunto, 1992)

\begin{tabular}{cc}
\hline Percentage $(\%)$ & Categories \\
\hline $0-20$ & Very Insufficient \\
$21-40$ & Insufficient \\
$41-60$ & Sufficient \\
$61-80$ & Valid \\
$81-100$ & Very Valid \\
\hline
\end{tabular}

3D Interactive Multimedia can be stated as valid as the learning media if the content and construct validity result percentage had more than $61 \%$ validity with the minimum score per aspect was 3 (Ismail, 2018, pp. 67-74).

\section{FINDINGS AND DISCUSSION}

The 3D interactive multimedia is the software that developed with .html5 based and can be operated on the various desktop browsers. It is a portable format and can 
present interactive molecular geometry concept through 3-dimensional molecular geometries that can be interacted in $360^{\circ}$, 2-dimensional molecular forms, and interactive quizzes that help the students to increase their visuospatial abilities. This multimedia is consisting of 7 menus. The landing page is the initial menu seen when this multimedia is activated. There are the instructions for use, the Author description, the language options, and the button to the home page that contains the 6 main menus. Home is the main page that contains the 6 main menus and provides a short description of the menus. This Multimedia is featured with two language options (bilingual), which is the Indonesian language that becomes the main language (default) and the English option that can be set on the Start page.
The introduction is a concept recognition menu, which begins with the type of basic competency and the introduction of molecular form geometry material. The phenomenon is a menu that displays natural events that occur due to the influence of molecular form geometry which is accompanied by short questions to practice understanding.

VSEPR theory is a menu that contains material related to VSEPR theory which is one of the methods used in the forecasting molecular forms. At the end of this menu, you will be presented with a visualization of molecular forms models based on the VSEPR theory in 2 dimensions and 3 dimensions.

Hybridization theory is a menu that contains material related to hybridization theory which is one of the methods used in the process of forecasting molecular

Figure 1. Landing Page

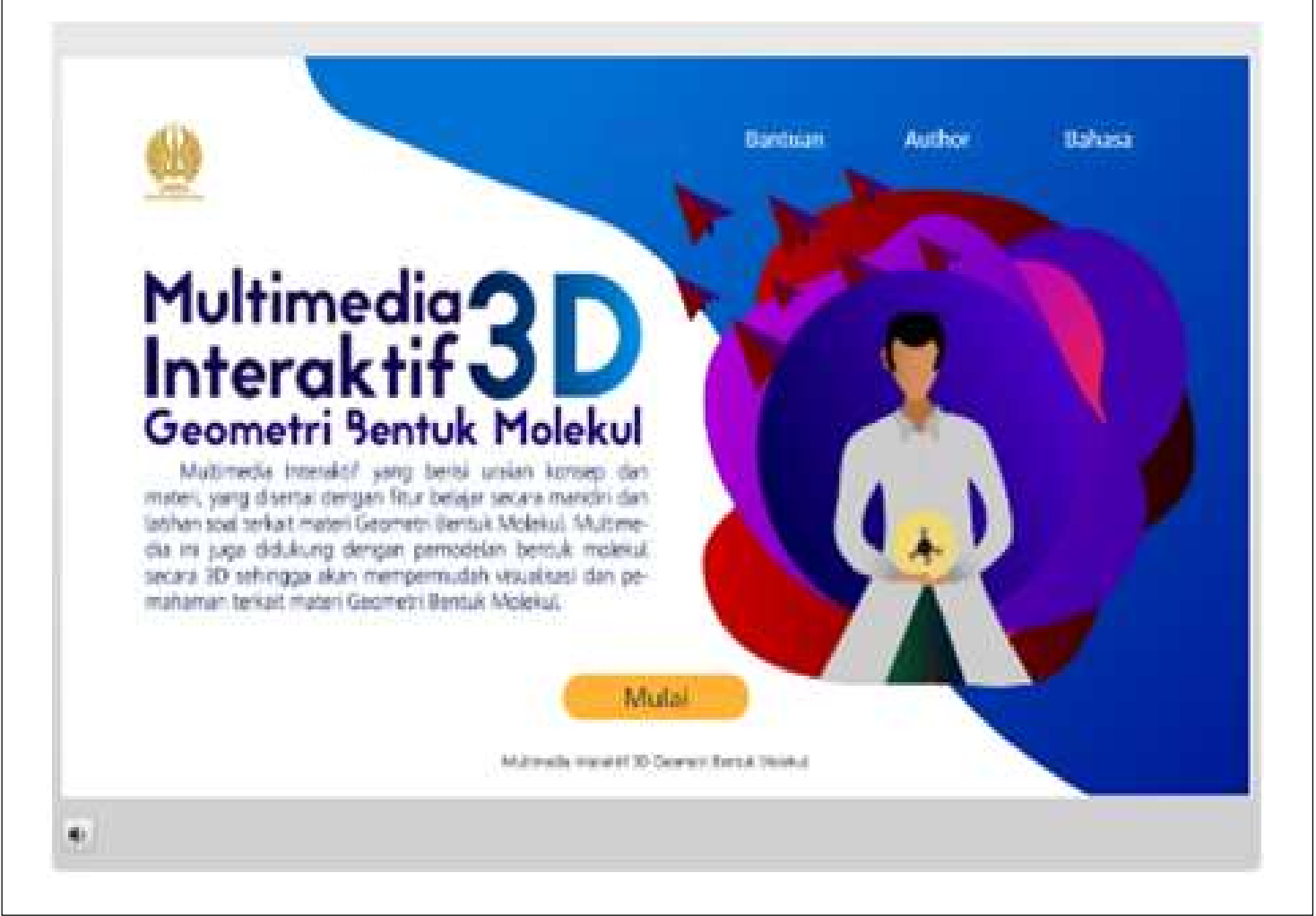


Figure 2. Home Screen

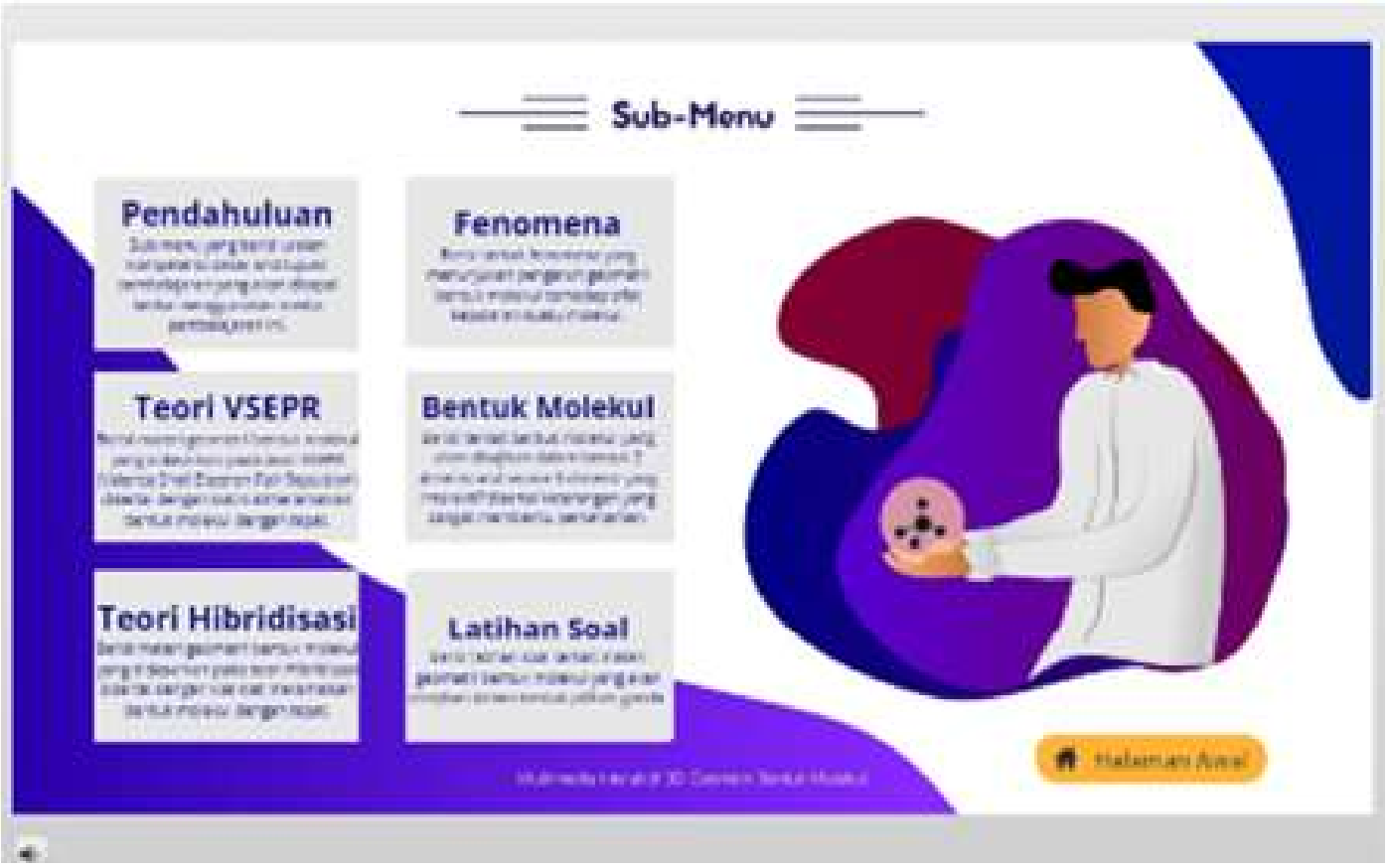

Figure 3. VSEPR Theory Menu

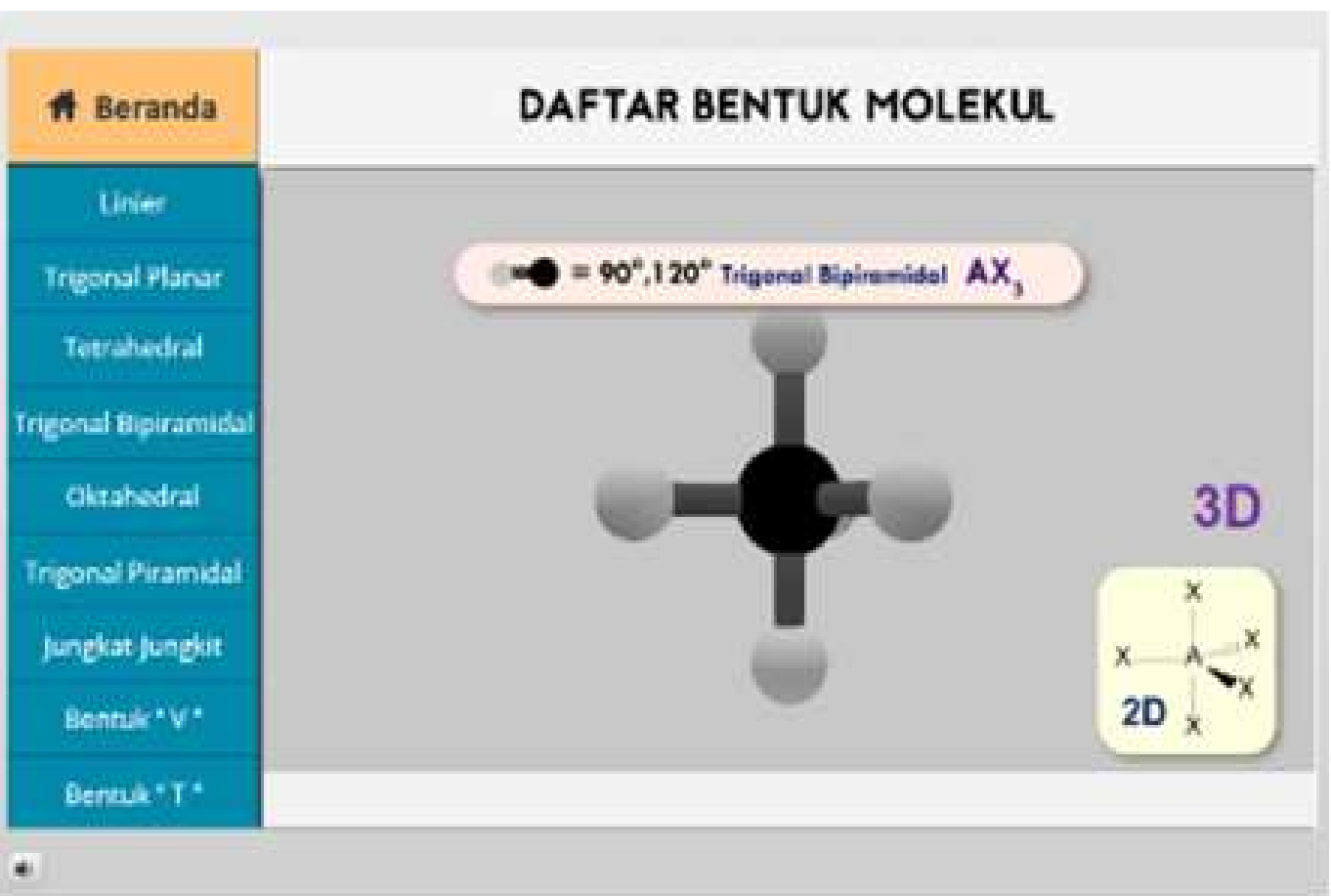


Figure 4. Hybridization Theory Menu

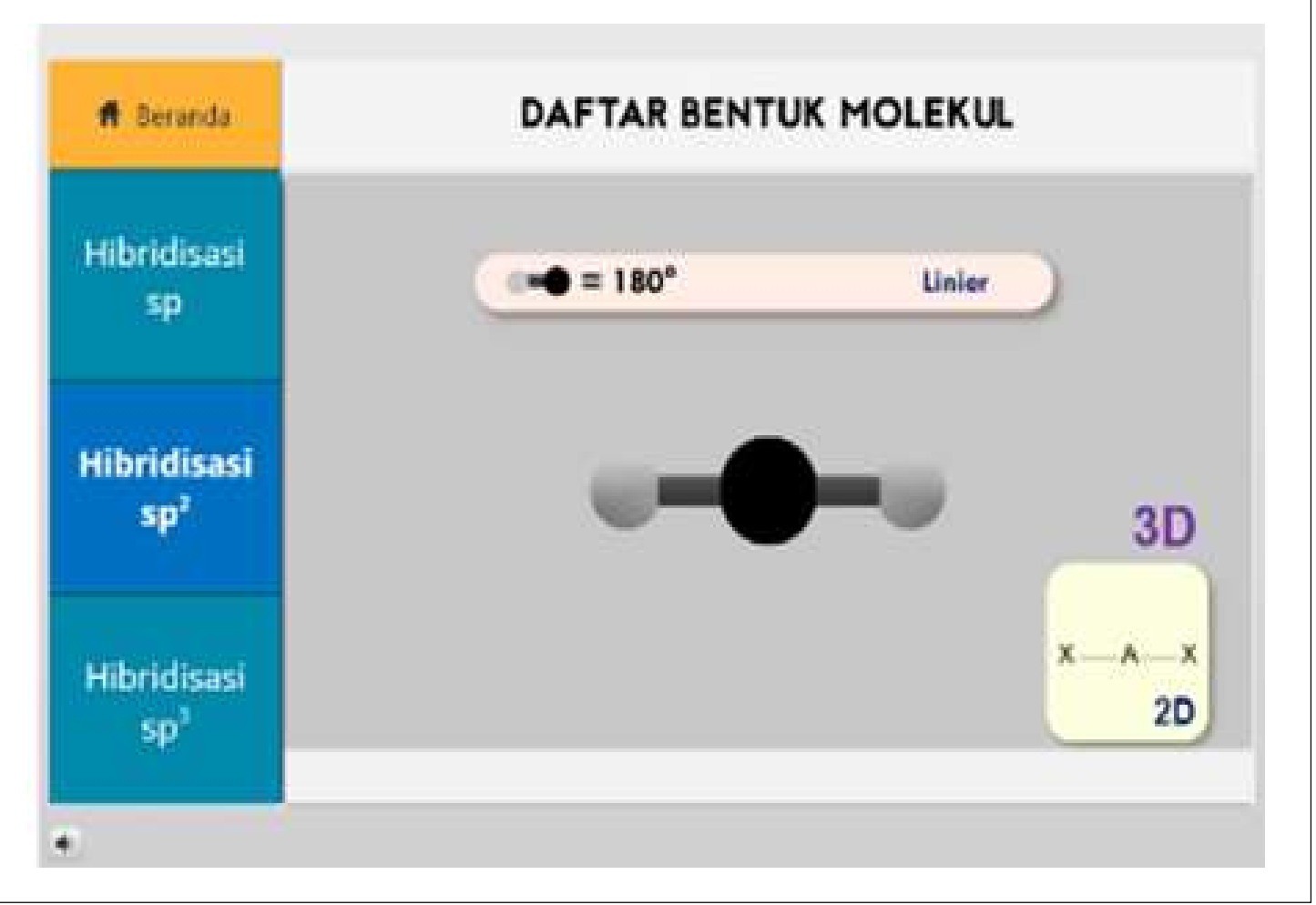

forms. At the end of this menu, you will be presented with the visualization of molecular forms models based on the theory of VSEPR in 2 dimensions and 3 dimensions.

The Nature of Molecular Shapes is a menu that presents the visualization of real molecular forms that exist in nature in 3 dimensions. So, learners can analyze differences in molecular-form models according to the VSEPR theory and hybridization with real molecular forms.

Exercise is a menu that contains exercises about sub-material geometric forms of molecules aimed at improving visual-spatial intelligence and understanding concepts.

Multimedia implementation is assessing to the experts in knowing the validation quality of interactive $3 \mathrm{D}$ multimedia. The assessment process is divided into two parts, the first is the study process, and the second is the validation process. The study process is occurring to obtain the suggestions to make the interactive 3D multimedia to be better. The study process result can be used as the suggestion to repair the interactive 3D multimedia. The suggestion of the study process is like the font kind and size selection, the illustration design, the arrangement of text and graphics, the guidance revision, and the remodel of molecular shapes 3D. After the revision, interactive 3D multimedia will be assessed on the validation process. The validation process is done by 3 validators that consist of two lecturers and one chemistry teacher. The assessment process is using a Likert scale from 1-5 that advance proceeds. The score will be represented into percentage interpretation validity. 
Figure 5. Nature of Molecular Shapes

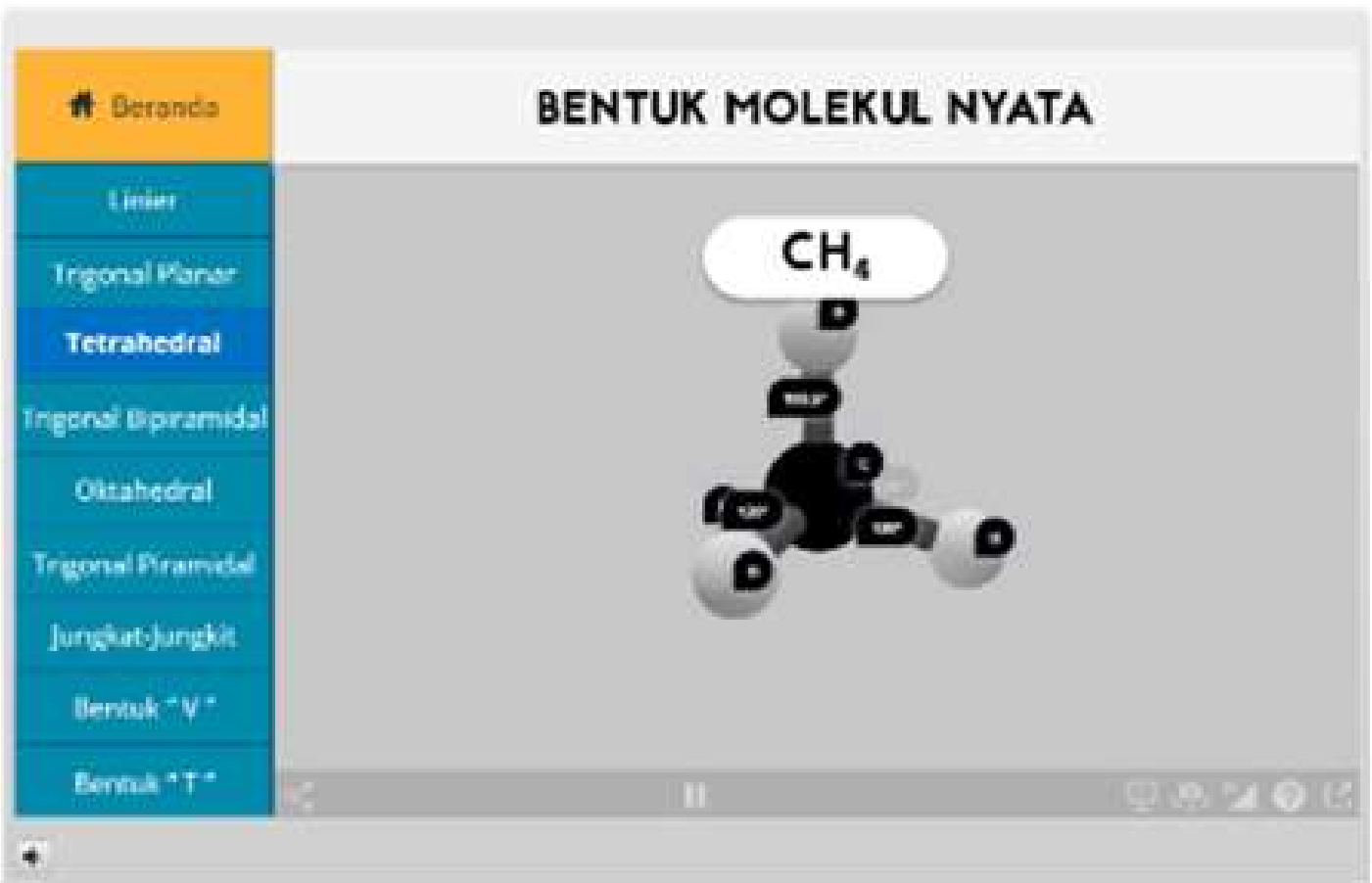

Figure 6. Exercise Menu

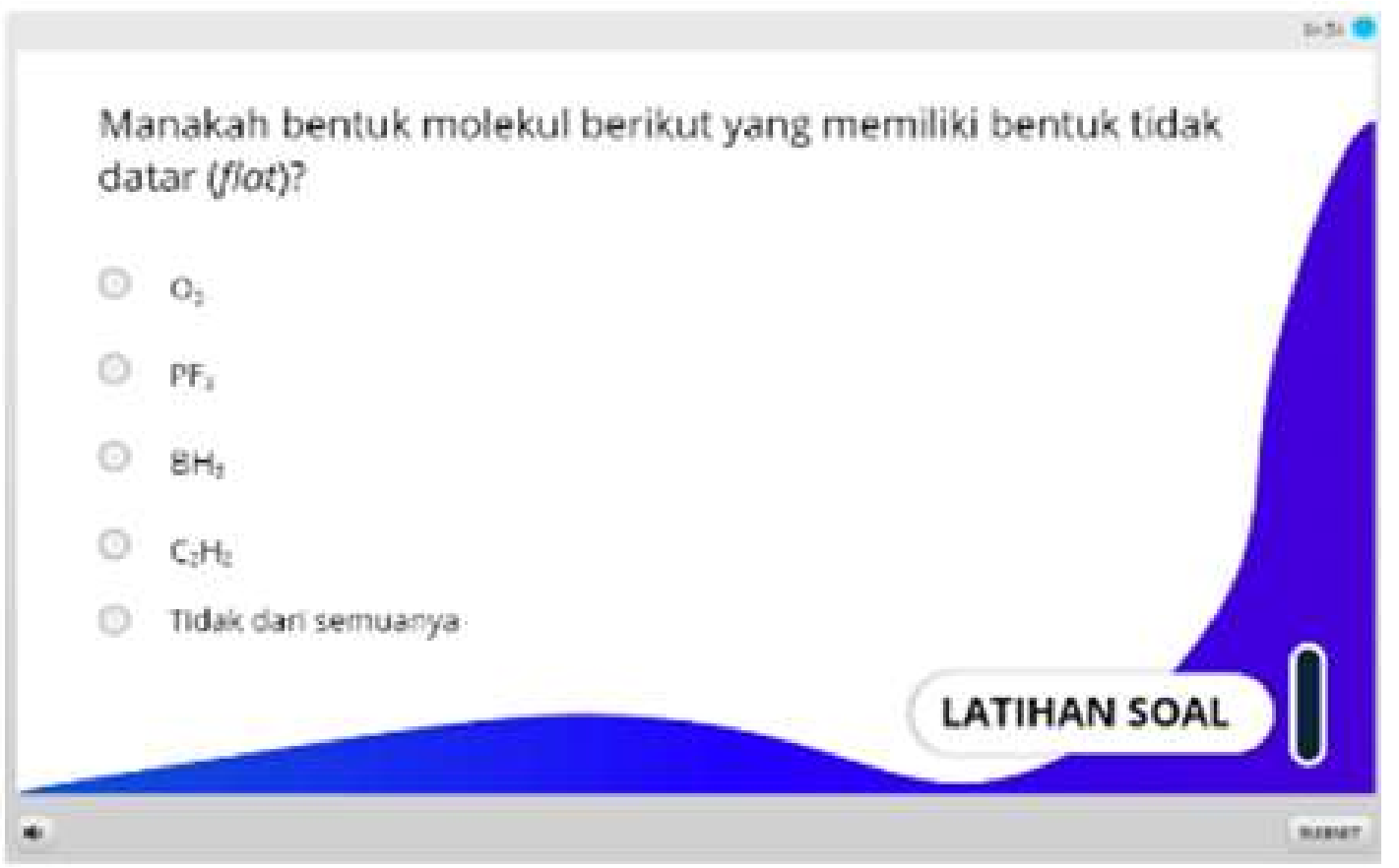


The content systematics criteria on the criteria of content validity is a criterion related to the linkage between the concepts of material and systematics in the evaluation. These criteria can be reviewed based on ease of understanding, clarity of logic flows, clarity of discussion descriptions, and accuracy of evaluation. Simply put, the content systematics in 3D Interactive multimedia is contained in storyboards and flowcharts that have been designed.
The average content standard criteria percentage in content validity has $82 \%$ validity with the $73 \%$ validity of scope and depth of learning objectives. This result means interactive multimedia has less scope and learning objectives are caused by the objective focus on the molecular shapes prediction method. It makes the multimedia only focus on the students' ability to predict molecular shapes and does not explain the detailed information about molecular shapes geometry matter. The

Table 3

Content Validity Summaries

\begin{tabular}{|c|c|c|c|c|c|c|}
\hline \multirow{2}{*}{ Number } & \multirow{2}{*}{ The Aspects } & \multicolumn{3}{|c|}{ Validator } & \multirow{2}{*}{ Percentage } & \multirow{2}{*}{ Criterion } \\
\hline & & 1 & 2 & 3 & & \\
\hline \multicolumn{7}{|c|}{ Content Standard } \\
\hline \multirow{2}{*}{$\begin{array}{l}1 \\
2\end{array}$} & Clarity of learning objectives & 4 & 4 & 4 & $80 \%$ & Valid \\
\hline & $\begin{array}{l}\text { The relevance of learning } \\
\text { objectives with curriculum }\end{array}$ & 4 & 4 & 4 & $80 \%$ & Valid \\
\hline 3 & $\begin{array}{l}\text { Scope and depth of learning } \\
\text { objectives }\end{array}$ & 3 & 4 & 4 & $73 \%$ & Valid \\
\hline \multirow{2}{*}{$\begin{array}{l}4 \\
5\end{array}$} & Learning motivation & 5 & 5 & 4 & $93 \%$ & Very Valid \\
\hline & $\begin{array}{l}\text { Completeness and quality of } \\
\text { learning aid materials }\end{array}$ & 4 & 4 & 4 & $80 \%$ & Valid \\
\hline 6 & $\begin{array}{l}\text { Material suitability with learning } \\
\text { objectives }\end{array}$ & 5 & 4 & 4 & $87 \%$ & Very Valid \\
\hline 7 & Depth of material & 4 & 4 & 4 & $80 \%$ & Valid \\
\hline \multicolumn{2}{|l|}{ Total } & 29 & 29 & 28 & $82 \%$ & Very Valid \\
\hline \multicolumn{7}{|c|}{ Content Systematics } \\
\hline 1 & Easy to understand & 4 & 4 & 4 & $80 \%$ & Valid \\
\hline 2 & Flow logic clarities & 4 & 4 & 4 & $80 \%$ & Valid \\
\hline 3 & $\begin{array}{l}\text { Clarity of explanation, discussion, } \\
\text { example, simulation, exercise }\end{array}$ & 4 & 4 & 4 & $80 \%$ & Valid \\
\hline 4 & $\begin{array}{l}\text { Evaluation consistency with } \\
\text { learning objectives }\end{array}$ & 5 & 4 & 4 & $87 \%$ & Very Valid \\
\hline 5 & $\begin{array}{l}\text { Accuracy and determination of } \\
\text { evaluation tools }\end{array}$ & 4 & 4 & 4 & $80 \%$ & Valid \\
\hline 6 & $\begin{array}{l}\text { Giving feedback on evaluation } \\
\text { results }\end{array}$ & 4 & 4 & 4 & $80 \%$ & Valid \\
\hline Total & & 25 & 24 & 24 & $81 \%$ & Very Valid \\
\hline
\end{tabular}


learning motivation aspect in this criterion has $93 \%$ of validity caused by the presence of supporting media like solution flow changes phenomenon that makes students' interest increasing and motivating them to learn. The use of a phenomenon in media resources is important to make a simple view from the student perspective before learning with the media (Clark \& Mayer, 2016, pp. 46-58).

The evaluation consistency aspect in content systematics criterium has $87 \%$ of validity that caused by the presence of exercise part in every multimedia menus. Evaluation consistency means the multimedia has the same standard exercise model in every menu. Consistency is one of the multimedia principles needed to involve students' cognitive skills (Giessen, 2014).

Based on the validation result data of interactive multimedia 3D geometry of molecular form, 3D Interactive multimedia geometry of molecular form can be expressed very valid based on the standard criteria of the contents with an average percentage of the validity of the content of $82 \%$ With a very valid category. On the content systematics criteria, the 3D Interactive multimedia geometry of the molecular form can be expressed very validly with an average percentage of the validity of the content of $81 \%$ with a very valid category. This result following the minimum percentage of a learning medium is considered valid if it has a validity percentage of $\geq 61 \%$ with a valid category (Ismail, 2018, pp. 67-74).

Construct validity is a criterion of validity that relates to the consistency of material and concept with its delivery method. The validity of the construction in this study can be reviewed through two criteria: technical software and visual communication.
The technical aspects of the software on the construct validity criteria relate to the ease of installing 3D interactive multimedia across various computer devices. This aspect can be reviewed based on multimedia reliability, ease of maintenance, and simplicity in its installation process. Multimedia is said to be reliable when it can be executed properly, not easily hangs, crashes, or stops during installation. Multimedia is said to be easy in maintenance (maintainable) When multimedia is composed and designed with the flow of the presentation, organizing, and linkage between the menus is good so easy in understanding.

Aspects of visual communication on the criteria of the validity of the construction are criteria related to the ease of operation of interactive 3D multimedia geometry of molecules. This aspect can be reviewed based on the clarity of video, language, and image in multimedia, the completeness of the usage instructions documentation, the quality of 3-dimensional models, and the completeness of the navigation.

The average percentage of software techniques is $78 \%$ in a valid category. The lowest percentage result is coming from the accuracies, interest, and usability with $73 \%$ of validity. This aspect means multimedia performance quality in the device. This multimedia can be operated by users in all kinds of browser computers that last updated in 2013 and so on. It makes several old browsers cannot operate it. The performance of multimedia is measured by media qualities and reliabilities (Zhao \& Chen, 2018).

The visual communication criteria have an average percentage result in $84 \%$ of validity with media clarities that have the highest percentage result than the others. Media clarities aspects relate with qualities of supported media like the 
Table 4

Construct Validity Summaries

\begin{tabular}{|c|c|c|c|c|c|c|}
\hline \multirow{2}{*}{ Number } & \multirow{2}{*}{ The Aspects } & \multicolumn{3}{|c|}{ Validator } & \multirow{2}{*}{ Percentage } & \multirow{2}{*}{ Criterion } \\
\hline & & 1 & 2 & 3 & & \\
\hline \multicolumn{7}{|c|}{ Software Techniques } \\
\hline 1 & Accuracies & 3 & 4 & 4 & $73 \%$ & Valid \\
\hline 2 & Reliable & 4 & 4 & 4 & $80 \%$ & Valid \\
\hline 3 & Maintainable & 4 & 4 & 4 & $80 \%$ & Valid \\
\hline 4 & Usability & 3 & 4 & 4 & $73 \%$ & Valid \\
\hline 5 & Interest & 3 & 4 & 4 & $73 \%$ & Valid \\
\hline 6 & Compatibility & 4 & 5 & 4 & $87 \%$ & Very Valid \\
\hline 7 & Installation Process & 25 & 29 & 28 & $78 \%$ & Valid \\
\hline Total & & 25 & 29 & 28 & $78 \%$ & Valid \\
\hline \multicolumn{7}{|c|}{ Visual Communication } \\
\hline 1 & Media Clarities & 5 & 4 & 5 & $93 \%$ & Very Valid \\
\hline 2 & Sustainability Media Assets & 4 & 4 & 4 & $80 \%$ & Valid \\
\hline 3 & 3D Models Quality & 5 & 4 & 4 & $87 \%$ & Very Valid \\
\hline 4 & Visual Design & 4 & 4 & 4 & $80 \%$ & Valid \\
\hline 5 & Interactivity & 4 & 4 & 4 & $80 \%$ & Valid \\
\hline 6 & Animation and Movie & 5 & 4 & 4 & $87 \%$ & Very Valid \\
\hline Total & & 27 & 24 & 25 & $84 \%$ & Very Valid \\
\hline
\end{tabular}

animation, graphics, and layout that increase student's interest and understanding. These clarities properly needed to support media performance and to make user experiences more comfortable (Rajendra \& Sudana, 2018). Moreover, the learning media that has great clarities can stimulate the students to increase their motivation and help better understanding (Priyambodo, Wiyarsi, \& Permanasari., 2012). This result is reinforced by (Winarti, Rahmini, \& Almubarak., 2019) that state that the clarities aspect has important rules to improve the students to think more critically.

Interactive multimedia based on $3 \mathrm{D}$ visualization of the sub-material geometry of a molecule form is a learning medium that has the criteria of each so that aspects in the criteria of content validity and construction can be grouped according to multimedia criteria, interactive criteria, and good visualization criteria. Here is a grouping of assessment aspects in each criterion.

Based on the validation result data of interactive multimedia 3D geometry of molecular form, Interactive 3D multimedia geometry molecular shapes can be expressed very valid based on the content validity and construct validity result. This result following the minimum percentage of a learning medium is considered valid if it has a validity percentage of $\geq 61 \%$ with a valid category (Ismail, 2018, p. 67).

Based on the grouping of validation results according to multimedia, interactive, and $3 \mathrm{D}$ visualization criteria, a multimedia validity percentage of $82 \%-87 \%$ is achieved with a high valid category. This corresponds to the minimum criteria of learning media validity $\geq 61 \%$ in a valid category. This result indicates that the development of 
Table 5

Interactive 3D Multimedia Validity Summaries

\begin{tabular}{|c|c|c|c|c|c|c|}
\hline \multirow{2}{*}{ Number } & \multirow{2}{*}{ The Aspects } & \multicolumn{3}{|c|}{ Validator } & \multirow{2}{*}{ Percentage } & \multirow{2}{*}{ Criterion } \\
\hline & & 1 & 2 & 3 & & \\
\hline \multicolumn{7}{|c|}{ Multimedia Characteristics } \\
\hline 1 & Video Clarities & 5 & 4 & 5 & $93 \%$ & Very Valid \\
\hline 2 & Visual Design & 4 & 4 & 4 & $80 \%$ & Valid \\
\hline Total & & 9 & 8 & 9 & $87 \%$ & Very Valid \\
\hline \multicolumn{7}{|c|}{ Interactive Characteristics } \\
\hline 1 & Interactivity & 4 & 4 & 4 & $80 \%$ & Valid \\
\hline 2 & Evaluation consistency & 5 & 4 & 4 & $87 \%$ & Very Valid \\
\hline 3 & Evaluation tools accuracy & 4 & 4 & 4 & $80 \%$ & Valid \\
\hline 4 & Giving feedback on evaluation results & 4 & 4 & 4 & $80 \%$ & Valid \\
\hline Total & & 4 & 4 & 4 & $80 \%$ & Valid \\
\hline \multicolumn{7}{|c|}{ Visualization Characteristics } \\
\hline 1 & Three-dimensional model quality & 5 & 4 & 4 & $87 \%$ & Very Valid \\
\hline 2 & Moving Media (animation, movie) & 5 & 4 & 4 & $87 \%$ & Very Valid \\
\hline Total & & 10 & 8 & 8 & $87 \%$ & Very Valid \\
\hline
\end{tabular}

Figure 7. Percentage Chart of Each Criteria

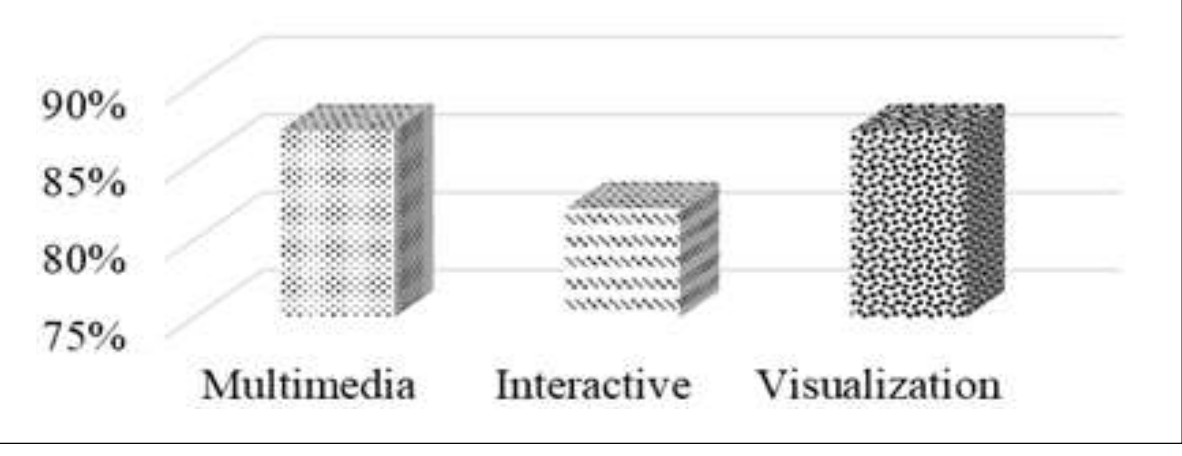

this multimedia is needed to be applied as the learning media that help the students' visuospatial abilities. The combination between 2-dimensional and 3-dimensional molecular models and the use of visual models can contribute to increasing the students visuospatial. The use of the learning media that has this characteristic properly needed to be applied to the other same characteristic materials, so that, the students' understanding is not depending on the assumption or the imagination, but based on the high representational skills as the outcomes of proper learning media.

\section{CONCLUSION}

The 3D interactive multimedia that has been validated by several processes, Based on the validation result, the percentage result of content validity at $81,5 \%$ with the valid category and construct validity as $81 \%$ with the high valid category. It makes the 
interactive 3D multimedia can be states as valid as the learning media that can increase the students' visuospatial intelligence on molecular geometry sub-matter.

\section{REFERENCES}

Arikunto, S. (1992). Prosedur penelitian (V). Jakarta: Rineka Cipta.

Baloyi, L. L., Ojo, S. O., \& Van Wyk, E. A. (2017). Design and development of an interactive multimedia simulation for augmenting the teaching and learning of programming concepts. ERIC, 6793.

Becker, N., Stanford, C., Towns, M., \& Cole, R. (2015). Translating across macroscopic, submicroscopic, and symbolic levels: The role of instructor facilitation in an inquiryoriented physical chemistry class. Chemistry Education Research and Practice, 16(4), 769-785. https://doi. org/10.1039/c5rp00064e.

Carlisle, D., Tyson, J., \& Nieswandt, M. (2015). Fostering spatial skill acquisition by general chemistry students. Chemistry Education Research and Practice, 16(3), 478-517. https://doi.org/10.1039/c4rp00228h.

Clark, R.C.,\& Mayer,R.E.(2016).E-learning and the science of instruction: Proven guidelines for consumers and designers of multimedia learning. New Jersey: John Wiley \& Sons.

Daryanto. (2013). Media pembelajaran. Yogyakarta: Gava Media.

Ghibaudi,E., Cerruti,L., \& Villani, G. (2019). Structure, shape, topology: Entangled concepts in molecular chemistry. Foundations of Chemistry, 22, 279-307. https://doi.org/10.1007/ s10698-019-09333-8.

Giessen, H. (2014). Media-based learning: A Theoretical metastudy. European Scientific Journal, 10(32), 16-29.
Ibrahim, M. (2001). Model pengembangan perangkat pembelajaran menurut Jerold E. Kemp \& Thiagarajan. Surabaya: PSMS-PPS UNESA.

Ismail, H. (2018). Statistika untuk penelitian pendidikan dan ilmu-ilmu sosial. Bandung: PT Kencana.

Manahan, S. (2017). Environmental chemistry (10 ${ }^{\text {th }}$ ed.). Boca Raton:CRCPress. https:// doi.org/10.1201/9781315160474.

McCollum, B. M., Regier, L., Leong, J., Simpson, S., \& Sterner, S. (2014). The effects of using touch-screen devices on students' molecular visualization and representational competence skills. Journal of Chemical Education, 91(11), 1810-1817. https://doi. org/10.1021/ed400674v.

Merchant, Z., Goetz, E. T., KeeneyKennicutt, W., Cifuentes, L., Kwok, O., \& Davis, T. J. (2013). Exploring $3-\mathrm{D}$ virtual reality technology for spatial ability and chemistry achievement. Journal of Computer Assisted Learning, 29(6), 579-590. https://doi.org/10.1111/jcal.12018.

Priyambodo, E., Wiyarsi, A., \& Permanasari, L. (2012). Pengaruh media pembelajaran interaktif berbasis web terhadap motivasi belajar mahasiswa. Jurnal Kependidikan: Penelitian Inovasi Pembelajaran, 42(2), 99-109. https:// doi.org/10.21831/jk.v42i2.2236.

Rajendra, I. M., \& Sudana, I. M. (2018). The influence of interactive multimedia technology to enhance achievement students on practice skills in mechanical technology. Journal of Physics: Conference Series, 953, 012-104.

Sunyono, \& Meristin, A. (2018). The effect of multiple representation-based learning (MRL) to increase students' understanding of chemical bonding concepts. Jurnal Pendidikan IPA 
Indonesia, 7(4), 399-406. https://doi. org/10.15294/jpii.v7i4.16219.

Sunyono, \& Sudjarwo. (2018). Mental models of atomic structure concepts of $11^{\text {th }}$-grade chemistry students. AsiaPacific Forum on Science Learning and Teaching, 19(1), 1-21.

Suprapto, P. K., bin Ahmad, M. Z., Chaidir, D. M., Ardiansyah, R., \& Diella, D. (2018). Spatial intelligence and students' achievement to support creativity in visuospatial-based learning. Jurnal Pendidikan IPA Indonesia, 7(2), 224-231. https://doi. org/10.15294/jpii.v7i2.14322.

Trés, E. S., \& Brucki, S. M. D. (2014). Visuospatial processing: A review from basic to current concepts. Dementia e Neuropsychologia, 8(2), 175-181. https://doi.org/10.1590/ S1980-57642014DN82000014.
Winarti, A., Rahmini, A., \& Almubarak, A. (2019). The effectiveness of multiple intelligences based collaborative problem solving to improve critical thinking. Jurnal Kependidikan: Penelitian Inovasi Pembelajaran, 3(2), 172-186. https://doi.org/10.21831/ jk.v3i2.24714

Wu, H.-K., \& Shah, P. (2014). Exploring visuospatial thinking in chemistry learning. Science Education, 88(3), 465-492. https://doi.org/10.1002/ sce.10126.

Zhao, M., \& Chen, Y. (2018). Visual enhancement algorithm of 3D virtual interactive multimedia images. Journal of Discrete Mathematical Sciences and Cryptography, 21(2), 387-392. https:// doi.org/10.1080/09720529.2018.144 9319. 